Research Article

J Exp Clin Med

2021; 38(2): 61-65

doi: $10.52142 /$ omujecm.38.2.2

\title{
Does costal cartilage resection reduce lung volume? (An experimental stereological study)
}

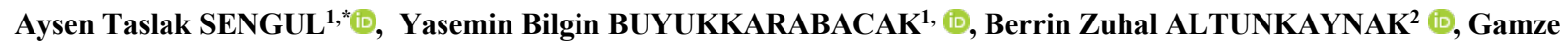

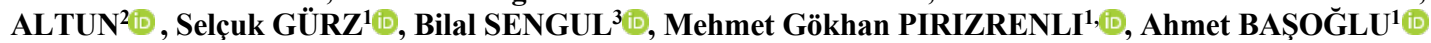 \\ ${ }^{1}$ Department of Thoracic Surgery, Ondokuz Mayıs University, Medical School Samsun, Turkey \\ ${ }^{2}$ Department of Histology and Embryology, Ondokuz Mayis University, Medical School, Turkey \\ ${ }^{3}$ Department of Pulmonary Disease, University of Health Sciences, Samsun Health Research Hospital, Samsun, Turkey
}

Received: 22.06 .2020

Accepted/Published Online: 09.12.2020

$\bullet$

Final Version: 14.03.2021

\begin{abstract}
Surgical treatment of chest wall deformities is done with costal cartilage resection in selected patients in adolescence. In this study, we evaluated the effect of costal cartilage resections on the lung volume stereologically by using computed tomography. In this study, sixteen four weeks old New Zealand rabbits were used. Young subjects were preferred to evaluate the effect of the operation on the growth process. In order to avoid postoperative complications, only two costal cartilage resections were performed. In the surgical group the right 4 th and $5^{\text {th }}$ costal cartilages were resected $(n=8)$. The group that was not operated was accepted as the control group $(\mathrm{n}=8)$. The growth of the subjects was followed. Computed thorax tomography (CTT) scans of all animals were performed preoperatively and at the 4th postoperative week. Estimation of pre- and postoperative lung volumes was performed with the Cavalieri's principle. In the control group followed up during growth, bilateral lung volumes were increased $(15.75 \%$ and $20.62 \%$ respectively right and left lungs). In the surgical group, both the surgical side and the opposite lung volume decreased after costal cartilage resection (20.09\% and $1.07 \%$ respectively right and left lungs). Even though the number of resected cartilages was limited, total lung volume decreased after costal cartilage resection. In the treatment of chest wall deformities, costal cartilage resection should be considered as the last option in children.
\end{abstract}

Keywords: Pectus excavatum, Cavalieri's principal, costal cartilage, lung

\section{Introduction}

Chest wall deformities are congenital anomalies, and they become more prominent during adolescence. Most patients have aesthetic concerns. In addition, this clinical condition is accompanied by depression. They complain about exercise intolerance, even though it cannot be usually detected physiologically. These complaints can affect the life quality (Kelly et al., 2008; Ji et al., 2011; Bostanc1 et al., 2013; Lomholt et al., 2016). A small proportion of chest wall deformity patients experience health complaints related to respiratory or cardiovascular system.

Surgical treatment is suggested to be performed at an early age period. In the Rawitch technique, bilateral deformed costal cartilage resection is usually performed. However, costal cartilage resection can result in serious complications such as relapse and chest wall instability in early age patients
(Calik et al., 2007). The most important question is whether this surgery performed for aesthetic purposes in adolescents has a negative effect on postoperative respiratory capacity.

So, in this study, we aimed to evaluate the effect of cartilage resection treatment on postoperative lung volume changes by using stereological methods.

\section{Materials and methods}

\subsection{Experimental procedure}

Sixteen 4-weeks-oldNew Zealand rabbits were supplied by the Application and Research Centre of Experimental Animals, Ondokuz Mayıs University. Each rabbit was placed individually in an air-conditioned room. The room temperature was $22-25^{\circ} \mathrm{C}$ with $30-70 \%$ relative humidity. The rabbits were kept in a 12- $\mathrm{h}$ light/dark cycle and allowed to feed standard pellets and tap water ad libitum throughout 
the experimental process. In addition, all experimental procedures were performed according to the protocols of the Local Animal Ethics Committee, Ondokuz Mayıs University.

The rabbits were randomly divided into two groups and the groups were designed as surgery group $(n=8)$ and control group $(n=8)$ which consisted of non-operated subjects. To avoid a possible paradoxical respiration, we resected two cartilages of each rabbit. In the surgery group, $4^{\text {th }}$ and $5^{\text {th }}$ right costal cartilages were resected. Also, the costo-chondral junction and perichondral sheath were preserved in each rabbit. Each group underwent computed thorax tomography (CT) preoperatively and 4 weeks later after the surgery.

\subsection{Surgical method}

In the surgical group, rabbits were anesthetized with intramuscular administration of a mixture of $5 \mathrm{mg} / \mathrm{kg}$ xylazine hydrochloride and $35 \mathrm{mg} / \mathrm{kg}$ ketamine hydrochloride before the surgical procedures. In the case of necessity, the anesthesia was extended with $0.1 \mathrm{ml}$ of ketamine. Surgical procedures were performed by the same surgeon using standard surgical procedures. Cefuroxime $(30 \mathrm{mg} / \mathrm{kg})$ and analgesic agents were administered intramuscularly for 3 days before and after the surgery to prevent the risk of infection.

The rabbits were fixed in the supine position and shaved from the jugulum to the umbilicus. Then, they were sterilized with povidone iodine. A 3-cm midsternal incision was made down the median of the sternum. After the dissection of the right pectoral muscles and perichondral sheath, the costal cartilages of the 4 th and $5^{\text {th }}$ were removed. The perichondral sheath was closed with a suture using 4/0 polyglactin following the cartilage resection. Pectoral muscles were closed with $3 / 0$ polyglactin, and the skin was closed with $2 / 0$ polypropylene. No surgical operation was applied in the control group. The control group was only kept under followup throughout the study.

\subsection{Volumetric analysis}

Cavalieri's principle, which is one of the unbiased stereological methods, was used in the estimation of pre- and post-operative lung volumes using $\mathrm{CT}$ images according to systematic sampling strategy (Roberts et al., 2000). Left and right lung volumes were estimated separately for each animal. Software Image J (version 1.46) and Stereo Investigator 9.0 were used for the volumetric measurements. According to the first important rule of this principle, an unbiased estimate of the volume of an object of interest must be obtained by sectioning the object with a series of parallel planes separated by a fixed distance $(t)$ (Altunkaynak and Ozbek, 2009). To avoid bias, the first section must be selected at a uniform and random position in a constant interval of length $(t)$ and the serial sections which are obtained from the object must be taken from throughout the whole area. Sections were obtained using CT and projected onto a computer screen. Next, the outline of areas of the lungs on serial CT images was marked in Image J. Finally, the areas of interest on these section images were evaluated using Cavalieri's principle (Fig. 1). Point counting grids were used for area estimation of the section profiles $(k=5 \mathrm{~mm})$. The point density of the point grid was designed to obtain an appropriate coefficient of error (CE) for the serial CT transects of our study.

All points hitting the object of interest area were counted and the volume of each lung was estimated using the following formula:

$$
\text { Volume }=\mathrm{t} \times \mathrm{a} / \mathrm{p} \times \Sigma P
$$

" $t$ ", section thickness; "a/p", area of each point on the point counting grid; " $\Sigma \mathrm{P}$ ", total number of points hitting the area of interest. In this study, the $\mathrm{CE}$ and coefficient of variation $(\mathrm{CV})$ were estimated according to the formula by Gundersen and Jensen (Altunkaynak and Ozbek, 2009).

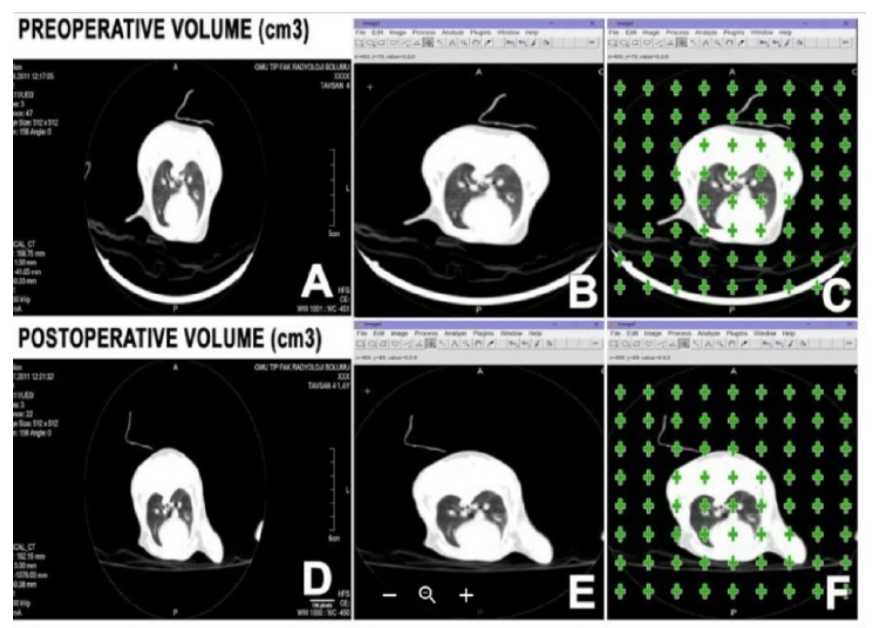

Fig. 1. Stereological procedures for applying the Cavalieri principle for the volume estimation on CT images of the pre-operative (A-C) and post-operative lung (D-F) using image $J$ program

\subsection{Statistical analyses}

Microsoft ${ }^{\circledR}$ SPSS Version 21.0 was used for statistical analyses. In comparison of groups, t-test; Paired t test was used to compare preoperative and postoperative volumes.

\section{Results}

The lung volume measurements were performed stereological methods by CTT in the preoperative and postoperative 1st month. In surgery group, the lung volume was $43.3 \pm$ $7.91 \mathrm{~cm}^{3} / 38.33 \pm 7.76 \mathrm{~cm}^{3}$ in preoperative and postoperative $1^{\text {st }}$ month, respectively. In the control group, the lung volume was $39.76 \pm 3.82 \mathrm{~cm}^{3} / 46.82 \pm 3.22 \mathrm{~cm}^{3}$ in preoperative and after 1 month, respectively (Table 1,2 ).

In the control group, an increase of $15.7 \%$ and $20.6 \%$ was observed in the right and left lung volumes, respectively. In the surgery group, there was $20.09 \%$ decrease in the postoperative volume of the right lung which underwent resection of the $4^{\text {th }}$ and $5^{\text {th }}$ costal cartilages ( $p$ 0.018), and there was $1.07 \%$ decrease in the volume of the left lung which was untreated side (Fig. 2). Reduction in right lung volume was statistically significant in surgical group when compared between groups $(p<0.001)$ (Table 3$)$. 
Table 1. Lung volume in surgery group

\begin{tabular}{|c|c|c|c|c|c|}
\hline n (8) & Preoperative & Postoperative & Volume change $(\%)$ & $\mathrm{t}$ & $P$ \\
\hline $\operatorname{TLV}\left(\mathrm{cm}^{3}\right)$ & $43.3 \pm 7.91$ & $\begin{array}{c}38.33 \pm \\
7.76\end{array}$ & -9.49 & 1.620 & 0.140 \\
\hline $\operatorname{RLV}\left(\mathrm{cm}^{3}\right)$ & $23.68 \pm 4.75$ & $\begin{array}{c}18.93 \pm \\
3.15\end{array}$ & -17.54 & 2.877 & 0.018 \\
\hline $\operatorname{LLV}\left(\mathbf{c m}^{3}\right)$ & $19.61 \pm 3.64$ & $\begin{array}{c}19.40 \pm \\
5.16\end{array}$ & -1.07 & 0.134 & 0.897 \\
\hline
\end{tabular}

Abbreviations; TLV, total lung volume; RLG, right lung volume; LLG, left lung volume

Table 2. Lung volume in control group

\begin{tabular}{cccccc} 
n $(8)$ & Preoperative & Postoperative & Volume change (\%) & t & P \\
\hline TLV $\left(\mathbf{c m}^{3}\right)$ & $39.76 \pm 3.82$ & $46.82 \pm 3.22$ & 17.76 & -4.259 & 0.013 \\
RLV $\left(\mathbf{c m}^{3}\right)$ & $23.33 \pm 4.32$ & $27.01 \pm 2.85$ & 15.75 & -1.874 & 0.134 \\
$\mathbf{L L V}\left(\mathbf{c m}^{3}\right)$ & $16.42 \pm 1.33$ & $19.81 \pm 2.00$ & 20.62 & -4.433 & 0.011
\end{tabular}

Abbreviations; TLV, total lung volume; RLG, right lung volume; LLG, left lung volume

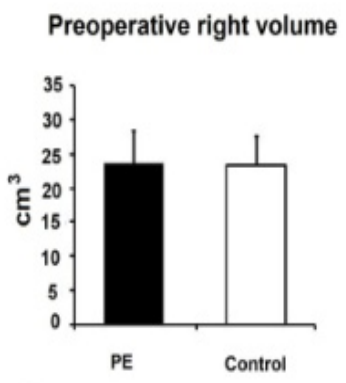

A
Postoperative right volume

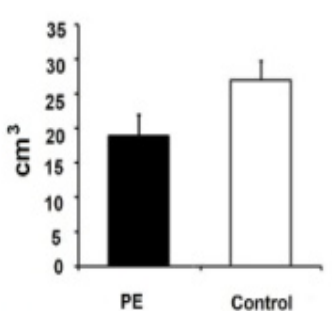

B
Preoperative left volume

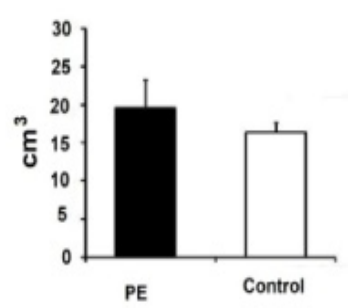

C
Postoperative left volume

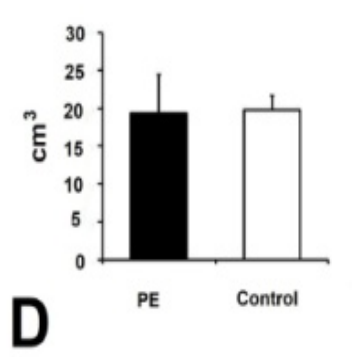

\section{Post-operative percent range}

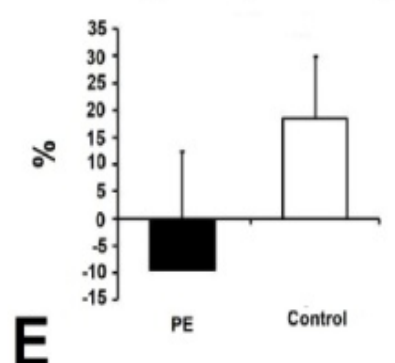

Fig. 2. Pre- and post-operative lung volumes estimated using the Cavalieri principle on CT images of all groups. The lung volumes were less than their preoperative volumes in the surgical group. There was difference among groups when evaluating post-operative total lung volume of non-operated (control) and operated (PE) groups $(\mathrm{p}<0.05)(\mathrm{A}-\mathrm{E})$

\section{Discussion}

Chest wall deformities are congenital diseases. These diseases show symptoms such as exercise intolerance, aesthetic anxiety, unwillingness to do sports (especially swimming), shyness, fatigue. Pulmonary and cardiac tests were generally normal in these patients. Sometimes these patients have complaints during severe exercise (Shamberger, 2000; Malek et al., 2003). Surgical treatment can be performed at any age. However, it is generally preferred in adolescence to prevent psychological and physiological consequences. The aim of surgical treatment of chest wall deformities is to achieve an effective aesthetic appearance and functional outcome without complication and mortality. However, preoperative complaints were evaluated with subjective data, and postoperative functional results could not be proven (Robicsek et al., 2009). Currently the benefits of surgical treatment on life quality, exercise tolerance and / or respiratory function are controversial.

In the literature, patients were evaluated pre and postoperatively with respiratory function tests and scales. In 
a multicenter study conducted by Kelly et al. with 11 centers, 247 patients with pectus excavatum (PE) were evaluated (Kelly et al., 2007). Although the patient's symptoms are thought to increase according to the degree of deformity, the preoperative psychosocial status of the patients was not consistent with the preoperative measured states. However, according to the results of the survey, it was seen that physical and psychosocial functions improved after surgery (Kelly et al., 2007; Bostanc1 et al., 2013). After Nuss and Rawitch, pre- and postoperative questionnaires (such as Pectus Excavatum Evaluation Questionnaire (PEEQ), Child Health Questionnaire (CHQ-CF87)) to evaluate the increase in quality of life reported that both surgical methods had similar quality of life, but it was not conclusive (Lam et al., 2008).

Table 3. Volume comparison of groups

\begin{tabular}{|c|c|ccc|}
\hline & $\begin{array}{c}\text { Surgery } \\
\text { group }\end{array}$ & $\begin{array}{c}\text { Control } \\
\text { group }\end{array}$ & $\mathbf{t}$ & $\mathbf{P}$ \\
\hline $\begin{array}{c}\text { Pre } \\
\text { TLV }\end{array}$ & $43.3 \pm 7.91$ & $39.76 \pm 3.82$ & 0.935 & 0.367 \\
\hline $\begin{array}{c}\text { Post } \\
\text { TLV }\end{array}$ & $38.33 \pm 7.76$ & $46.82 \pm 3.22$ & 2.313 & 0.038 \\
\hline $\begin{array}{c}\text { Pre } \\
\text { RLV }\end{array}$ & $23.68 \pm 4.75$ & $23.33 \pm 4.32$ & 0.137 & 0.893 \\
\hline $\begin{array}{l}\text { Post } \\
\text { RLV }\end{array}$ & $18.93 \pm 3.15$ & $27.01 \pm 2.85$ & 4.823 & $<0.001$ \\
\hline Preo & $19.61 \pm 3.64$ & $16.42 \pm 1.33$ & 1.867 & 0.085 \\
\hline LLV & & & & \\
\hline Post & $19.40 \pm 5.16$ & $19.81 \pm 2.00$ & 0.168 & 0.869 \\
\hline LLV & & & & \\
\hline
\end{tabular}

Abbreviations; TLV, total lung volume; RLG, right lung volume; LLG, left lung volume; pre, preoperative; post, postoperative

Conflicting results have been reported in studies with pulmonary function tests in chest wall deformities. In Goertzen et al.'s meta-analysis, no change in pulmonary functions after surgery in PE patients was found (Goertzen et al., 1993). Another study showed about $10 \%$ reduction in the pulmonary function in a three-year postoperative follow-up (Quigley et al., 1996). The respiratory effect is assessed by respiratory functions test in most studies. However, pulmonary function test measurement and answer of questionnaires are closely related to many factors such as patient compliance, psychological and physiological status. Therefore, discussing the effect of surgical treatment on respiratory system with pulmonary function tests and questionnaires are not considered to reflect the existing respiratory capacity. In our previous study, we demonstrated the increase in lung volume after Nuss surgery in PE patients with stereological method. Postoperative volume increase of $417 \pm 47.6 \mathrm{~mL}$ could not find correlation in respiratory function tests (Sengul et al., 2014). We believe that stereological methods should be used to obtain more realistic data. In our study, total lung volume was calculated independent of patient factor by performing stereological analyses on pre- and post-operative CT. The study revealed a significant decrease in the postoperative total lung volume compared to the control group, despite the protected costachondral junction and limited cartilage resection. Furthermore, in the surgical group, decrease in the lung volume was found not only in the hemithorax which underwent cartilage resection but also in the opposite hemithorax. So stereologically, cartilage resection has been shown to adversely affect the development of the thoracic wall and thus lung volume. Although spine anomalies (kyphosis, scoliosis) are prevented after thoracic wall deformity surgeries which are generally performed at an early age, it is evident that the problem continues to develop in the thorax wall. These results question the need for cartilage resection in the treatment of chest wall deformities because it is usually made for aesthetic purposes.

There are two options for surgical treatment; Ravitch procedure or minimally invasive surgery. The decision between these two options is discussed with advantages and disadvantages; the patient's clinic, the preference of the patient and his/her relatives, and the experience of the surgeon. In Ravitch procedure in pectus deformities, the common opinion is to prevent restrictive thoracic deformity by preserving the costa-chondral junction. All bilaterally deformed cartilages need to be removed in this surgery. However, restrictive thoracic deformities have been reported in this surgical method (Haje 1995; Robicsek and Fokin, 2004; Fokin and Robicsek, 2006) Minimal cartilage resection is recommended for the quick healing/recovery of the cartilage. In addition, decreased front and back chest wall diameters have been reported in studies on a limited number of cartilage resections (Calik et al., 2007). In this study, we evaluated the effect of cartilage resection on thoracic development in early age subjects. We also maintained costochondral junction as recommended. We have excised only one-sided two cartilages to reduce morbidity. However, we found that there was a decrease in the bilateral lung volume in surgery group compared to the control group.

Neither the preoperative respiratory effects nor the postoperative respiratory changes of pectus deformities can be standardized with the current available data. Survey results and pulmonary function tests are insufficient. To date, studies have been conducted with non-objective measurements and data represented by the answers (Moon et al., 2019). Evidence-based, control-group randomized trials are needed to evaluate changes in lung volume after surgical treatment of chest wall deformities.

Finally, we believe that the choice of Ravitch procedure in surgical treatment of thoracic wall deformities might increase the quality of life, but it will decrease post-operative lung 
volume. Therefore, treatment options without cartilage resection should be considered as a priority in chest wall deformities.

\section{Conflict of Interest}

The authors declared no conflicts of interest with respect to the authorship and/or publication of this article.

\section{Funding}

This study was funded by Ondokuz Mayis University Scientific Research Projects Unit.

\section{References}

1. Altunkaynak, B.Z., Ozbek, E., 2009. Overweight and structural alterations of the liver in female rats fed a high-fat diet: a stereological and histological study. Turk. J. Gastroenterol. 20:93-103.

2. Bostanci, K., Ozalper, M.H., Eldem, B., Ozyurtkan, M.O., Issaka, A., Ermerak, N.O., Yüksel, M., 2013. Quality of life of patients who have undergone the minimally invasive repair of pectuscarinatum.Eur. J. Cardiothorac. Surg. 43:122-126.

3. Calik, M., Aribas, O.K., Kanat, F., 2007. The effect of costal cartilage resection on the chest wall development: a morphometric evaluation. Eur. J. Cardiothorac. Surg. 32:756760.

4. Fokin, A.A., Robicsek, F., 2006. Acquired deformities of the anterior chest wallJ Thorac. Cardiovasc. Surg. 54: 57-61.

5. Goertzen, M., Baltzer, A., Schulitz, K.P., 1993. Long-term results after operation for funnel chest. Arch. Orthop. Trauma. Surg. 112:289-291.

6. Haje S.A., 1995. Iatrogenic pectus carinatum: A case report Int Orthop (SICOT). 19: 370-373.

7. Ji, Y., Liu, W., Chen, S., Xu, B., Tang, Y., Wang, X., Yang, G., Cao, L., 2011. Assessment of psychosocial functioning and its risk factors in children with pectus ex cavatum. Health. Qual. Life Outcomes.9: 28.

8. Lomholt, J.J., Jacobsen, E.B., Thastum, M., Pilegaard, H., 2016. A prospective study on quality of life in youths after pectus ex cavatum correction. Annals. Cardiothorac. Surg. 456-465.

9. Kelly, R.E. Jr, Shamberger, R.C., Mellins, R.B., Mitchell, K.K., Lawson, M.L., Oldham, K., Azizkhan, R.G., Hebra, A.V., Nuss, D., Goretsky, M.J., Sharp, R.J., Holcomb, G.W., Shim, W.K.T., Megison, S.M., Moss, R.L., Fecteau, A.H., Colombani, P.M., Bagley,T.C., Alan, B., Moskowitz, A.B., 2007. Prospective multicenter study of surgical correction of pectus excavatum: Design, perioperative complications, pain, and baseline pulmonary function facilitated by internet-based data collection. J. Am. Coll. Surg. 205: 205-216.

10. Kelly, R.E. Jr, Cash, T.F., Shamberger, R.C., Mitchell, K.K., Mellins, R.B., Mitchell, K.K., Lawson, M.L., Oldham, K., Azizkhan, R.G., Hebra, A.V., Nuss, D., Goretsky, M.J., Sharp, R.J., Holcomb, G.W., Shim, W.K.T., Megison, S.M., Moss, R.L., Fecteau, A.H., Colombani, P.M., Bagley, T.C., Alan, B., Moskowitz, A.B., 2008. Surgical repair of pectus excavatum markedly improves body image and perceived ability for physical activity: multicenter study. Pediatrics. 122: 1218-1222.

11. Lam, M.W., Klassen, A.F., Montgomery, C.J., LeBlanc, J.G., Skarsgard, E.D., 2008. Quality-of-life outcomes after surgical correction of pectus excavatum: a comparison of the Ravitch and Nuss procedures. J. Pediatr. Surg. 43:819-825.

12. Malek, H.M., Fonkalsrud, E.W., Cooper, C.B., 2003. Ventilatory and cardiovascular responses to exercise in patients with pectus excavatum. Chest. 124: 870-882.

13. Moon, D.H., Kang, M.K., Lee, H.S., Lee, S., 2019. Long-Term Results of Compressive Brace Therapy for Pectus Carinatum.Thorac. Cardiovasc. Surg. 67:67-72.

14. Quigley, P.M., Haller, J.A. Jr, Jelus, K.L., Loughlin, G.M., Marcus, C.L., 1996. Cardiorespiratory function before and after corrective surgery in pectus ex cavatum. J. Pediatr. 128:638-643.

15. Roberts, N., Puddephat, M.J., McNulty, V., 2000. The benefit of stereology for quantitative radiology. Br. J. Radiol. 73:679-697.

16. Robicsek, F., Fokin, A.A., 2004. How not to do it: Restrictive thoracic dystrophy after pectus excavatum repair. Interact. Cardiovasc. Thorac. Surg. 3:566-568.

17. Robicsek, F., Watts, L.T., Fokin, A.A., 2009. Surgical Repair of Pectus Excavatum and Carinatum.Semin. Thorac. Cardiovasc. Surg. 21:64-75.

18. Shamberger, R.C., 2000.Cardiopulmonary effects of anterior chest wall deformities Chest. Surg. Clin. North. Am. 10: 245252.

19. Sengul, A.T., Sahin, B., Celenk, C., Basoglu, A., Sengul, B., 2014. The effect of minimally invasive surgical repair on the lung volumes of patients with pectus excavatum. Thorac. Cardiovasc. Surg. 62: 226-230. 